APRESENTAÇÃO 


\section{MEMORIA Y ACTUALIDAD DE UN MOVIMIENTO}

El dossier de este número de la Revista Caracol propone recordar y revisitar el legado de la Reforma Universitaria de 1918, un hecho que trascendió las fronteras de la Universidad Nacional de Córdoba (Argentina) y se convirtió en un emblema de diversos movimientos que cuestionarían el orden social imperante durante el siglo XX en América Latina.

Las razones del tema extrapolan lo meramente conmemorativo. En momentos en que en Brasil la universidad pública es objeto, como otras instituciones, de diversas amenazas a su autonomía y carácter democrático, creemos que la reflexión a partir de esta experiencia histórica nos ofrece la oportunidad de trazar alternativas a proyectos que vienen a socavar aún más lo que la universidad significa de resguardo, generación y difusión del conocimiento.

En este sentido, el ensayo que abre el dossier, "Dieciocho apuntes sobre el Dieciocho” de Eduardo Rinesi, realiza, en simbólicos dieciocho puntos, una lectura de diferentes aspectos del Manifiesto Liminar, evaluando además, la significación histórica de la Reforma y la contemporaneidad de su legado. Se trata de un texto que precisa la dimensión latinoamericana de la Reforma, y su conexión con otras experiencias de apertura social tanto a nivel local como internacional. A partir de esa lectura, el ensayo indaga además la actual discusión por la legitimidad de la universidad, o más bien de su expansión y entendimento como derecho. Después de ese artículo, presentamos una transripción del Manifiesto Liminar de 1918, acompañada por su versión al portugués, no sólo para que el lector pueda acompañar mejor las diversas referencias que Rinesi hace sobre esa proclama histórica, también porque su 
lectura cobra una vibrante actualidad en un contexto de operacionalización serializadora de la vida universitaria en el que, como afirmaban los jóvenes de la Reforma, la ciencia "pasa silenciosa o entra mutilada y grotesca al servicio burocrático".

Creemos que la discusión abierta por Rinesi dialoga muy bien con el ensayo de Diego Tatián, "La invención y la herencia. Notas liminares para una universidad abierta", ya que el mismo revisa los fundamentos que han cimentado la institución universitaria, tanto los europeos, que tiene a El conflicto de las facultades (1798) de Kant como texto nuclear, como los latinoamericanos desde la Reforma a nuestros días, en los que el debate se orienta a evaluar la proyección del paradigma neoliberal sobre el funcionamiento, financiación y finalidad de la universidad. La entrevista a Diego Tatián amplía los temas del ensayo, especialmente aquellos que se refieren al diálogo entre la tradición reformista y la universidad popular impulsada por el peronismo (que estableció, entre las décadas del 40 y 50, la gratuidad y la ausencia de exámenes de ingreso), tradiciones estas que hoy se presentarían como resistencia frente a los modelos hegemónicos que procuran reducir la universidad a una lógica empresarial de prestación de servicios.

Luego de estos trabajos que inquieren la actualidad de la Reforma del 18, el artículo de Javier Moyano, "La Reforma Universitaria Cordobesa de 1918: Contextos y Protagonistas", nos lleva al estudio de las condiciones políticas y sociales que posibilitaron ese movimento. Se trata de una minuciosa descripción sobre el momento histórico en que se da el acontecimento reformista. Este estudio tiene la ganancia de no quedarse en el análisis 
de la coyuntura nacional, sino que indaga la lógica política provincial específica de Córdoba, desbrozando sus tensiones y conflitos. Pensamos que la lectura de la génesis histórica de la Reforma luego del análisis de su contemporaneidad, permite una lectura "a contrapelo" que hace posible apreciar la resignificación de esta experiencia a lo largo del tiempo.

El dossier sigue con el análisis del estado de situación del ámbito universitario en dos países de América Latina: Venezuela y Perú. De esta manera, Eleonora Cróquer Pedrón en "El problema de la universidad en Venezuela y los lugares para su resistencia (im)posible en tiempos de postautonomía", presenta los limites y desafios de la enseñanza superior en el actual contexto político y económico venezolano. A partir del texto "Las pupilas de la Universidad. El principio de razón y la idea de Universidad" (1997) de Jacques Derrida, la autora reflexiona sobre las posibilidades de autonomía de la universidad en tiempos de deterioro institucional y material, destacando el papel de resistencia y salvaguarda que puede significar el trabajo de sus grupos de investigación. Por su parte, Gonzalo Espino Relucé en "La reforma, la Universidad San Marcos y los retos del humanismo" evalúa las perspectivas de la universidad más antigua del continente, dentro de los límites de la Nueva Ley Universitaria peruana (Ley n. 30220, del 3 julio de 2014). Se trata de un texto que pondera los conflitos entre una historia institucional de larguísima duración y las exigencias de una legislación que en muchos de sus aspectos promovería, según Gonzalo Relucé apoyado en conceptos de Boaventura de Sousa Santos, la pérdida de prioridad del bien público universitario. Ante ese panorama, el texto propone la perspectiva humanista abierta por el Allin kawsay, concepto andino que se abre como 
posibilidad decolonial. Pensamos que ambos textos dialogan entre sí, por abordar lo universitario desde la conflictividad de coyunturas que, si bien son de diferente naturaleza y tenor, exigen imaginar otros horizontes y posibilidades para la institución universitaria, y eso, este repensar la universidad desde el conflito, es lo que entendemos como el mayor legado de la Reforma del 18.

El dossier cierra con un artículo de María Teresa Celada, "As razóes da(s) língua(s). Na produção de conhecimento e na educação superior", que cuestiona el papel hegemónico del inglés como lengua de conocimiento en la universidad. Se trata de un punto también destacado por Tatián y que resulta especialmente significativo para las universidades latinoamericanas, asediadas por políticas institucionales monolíngües, frente a lo cual se hacen necesarias acciones que promuevan y aseguren la apertura a la diversidad lingüística.

En la sección "Varia" de este número incluimos cuatro artículos, tres de ellos sobre fenómenos literarios y culturales de Hispanoamérica y uno de España. En el texto "Literatura e História. Camilo José Cela e a narrativa espańola do pós-guerra" Edwirgens Ribeiro Lopes de Almeida encuadra dos novelas de Cela en momentos diferentes del proceso cultural y político español en la segunda mitad del siglo XX, para lo cual sus ejes de reflexión son la forma narrativa y los rasgos estéticos más abarcativos. El artículo "El final de Mariel como punto de partida. La disputa por José Martí desde el exilio cubano" analiza el homenaje a Martí que, en 1980, diversos escritores cubanos exiliados del régimen castrista realizan en una revista que publicaban primero en Nueva York y después en Miami. La autora expone su 
hipótesis de que ese homenaje renovó la recepción crítica consolidada sobre el escritor cubano, condicionada por uma memoria oficial impuesta que lo vinculaba a la figura de Castro y a su régimen. Ulla Szaszak, en su texto "Las tensiones entre lo global y lo local en Lumpérica, de Diamela Eltit", aborda esa novela chilena de la década de 1980 dando especial atención a procesos de nominación y subjetivación representados en ella. Para Szaszak, la tensión entre lo local y lo global en la novela se manifiesta, por un lado, en una focalización específica de lo nacional a partir de figuras marginalizadas, y, por otra, en el plano de las elecciones estéticas. El último artículo es "Josefina Plá: sobre alguma correspondência e suas transformaçôes", de Andre Rezende Benatti, que recorre diferentes dimensiones de la actividad cultural de esa crítica literaria, escritora y artista plástica paraguaya, dando especial atención a su vinculación con la obra de Federico García Lorca.

Incluimos también, cerrando el volumen, una entrevista con Pablo Rocca, profesor titular de la Universidad de la República, Uruguay, realizada por Bruno Mazolini de Barros y por Fábio Varela Nascimento, en la cual se discuten temas como la confomación de los sistemas literarios en América Latina y la internacionalización de esta literatura.

\section{Pablo Gasparini y Adrián Pablo Fanjul}

